\title{
Anti-social elements in Telugu drama serials - A study on Godavari District's women
}

\author{
K. Satya Savithri
}

Asst Professor of English, Bhimavaram Institute of Engineering \& Technology, Pennada Agraharam, Andhra Pradesh, India

\begin{abstract}
Women are like a fortress to the culture of India. These women, who are supposed to be the protectors of the wealth of Indian culture, it is the women, who gave birth to great people that earned fame across the world. It is the women, who struggled a lot to lead her life with virtues. $21^{\text {st }}$ century woman proved herself in all the fields. She maintains a home and manages an office. She is the very embodiment of love, care, honesty and chastity. This is the greatness of a woman. But the portrayal of woman in daily serials is quite different. Daily soap operas are showing women as a symbol of cruelty, selfishness and as an anti-social personality. Many studies revealed the impact of the serials but my attempt through this study analyses how women were portrayed in Telugu daily serials and the perception of the women especially who are living in Godavari districts.
\end{abstract}

Keywords-Anti-social elements in TV Serials, Telugu Drama, Godavari Districts women.

\section{INTRODUCTION}

East Godavari and west Godavari are popularly known as Godavari districts. These are situated in coastal region and the largest districts in the state of Andhra Pradesh, India. Once successively ruled by Mauryas, Sathavahanas, Vishnu Kundins, Eastern Chalukyas, Cholas, etc., and then by the British. Both districts were rich in culture and heritage. Godavari districts are populated with 92.22 lack people as per the Wikipedia sources. As per the recent statistics 4,512,920 females are there in the districts. Indian women play an important role in forecasting the culture but Godavari districts women has special providence in fostering the culture, continuing the legacy of family ethics, maintaining the joint families without any conflicts. Even in marriage proposals also most of the bridegrooms and their families look for brides from Godavari districts. This is the importance given to these women here. Unfortunately the value of women gradually deteriorated because of daily serials. Woman became a symbol of cruelty rather than chastity. Mostly Godavari districts wo men are house wives they spend most of their time in front of the televisions watching these Telugu drama serials. I want to elucidate the impact of these serials on their life style. Moreover what do they think by watching these soap operas constantly.
II. OBJECTIVES STUDY OF THIS STUDY
a) To identify the casting of extra- marital affairs in Telugu drama serials.
b) To find out that these serials are instigating anti- social behavior in women
c) To examine the cruelty of women in serials.
d) To know the influence of these serials in their day to day life
e) To understand the socio-cultural values in the serials.
f) To find out the cause for excessive romance in Telugu serials.

\section{LITERATURE REVIEW}

It has been observed that many studies have conducted globally and nationally to identify the effect of Television serials on our society irrespective of the age groups. They have studied extensively about these serials from different perspectives. Some have submitted their thesis on this very topic. But very few studied about Telugu drama serials.

Kaluvoya Anitha (2017) from St. Francis College for women from Hyderabad has studied about the Telugu serials content and the reason for addiction to these serials. Her study revealed that the government should interfere in this matter seriously and must appoint a regulatory body to monitor the content.

Humawon Sarkar (2016) researched on the Impact of Serials in our society: perception from different age groups. $\mathrm{He}$ found out that watching these serials regularly will have a bad affect on our values, beliefs, culture and on the total society.

\section{METHODS AND MATERIALS}

I collected the primary data by conducting a survey through questionnaire with in depth analysis and interviewed some of them personally for better understanding in the month of 
May 2019. I browsed the sites, referred journals and publications for secondary data.

A survey was conducted on 100 women from Godavari districts

College going undergraduate profes sionalstudents $=25$
Working women

Daily wage working women

House wives
$=25$

$=25$

$=25$

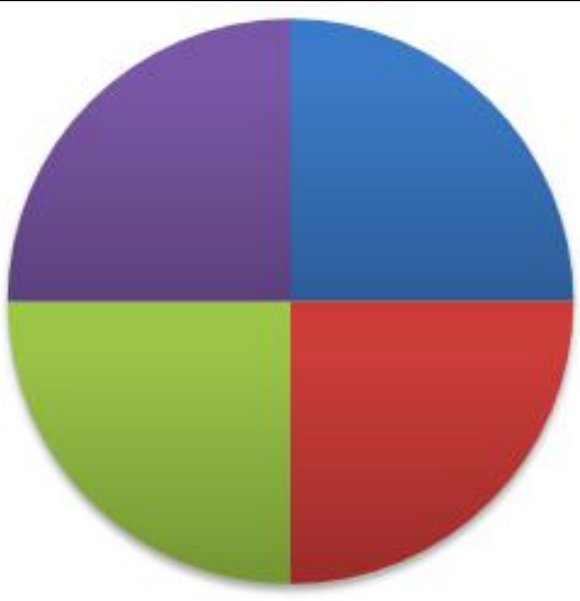

- College going under graduate professional students

Working women

Daily wage working women

House wives

\section{RESULTS AND DISCUSSION}

5.1 The casting of extra- marital affairs in Telugu drama serials.

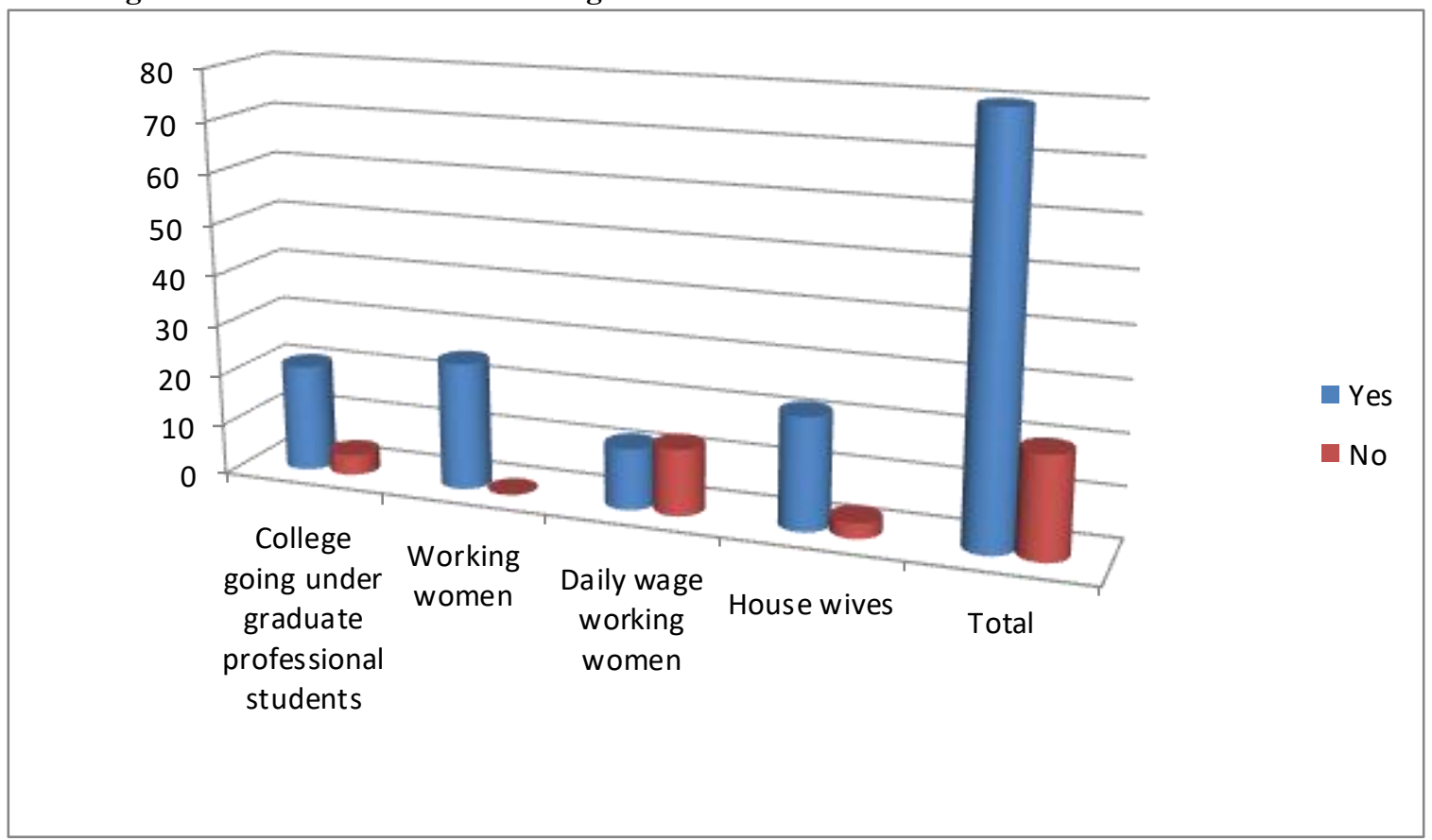


In total $80 \%$ of the result shown that television serials are casting extra marital affairs. Especially wo man in serials are attracted to the husband of another woman. These serials are lighting up an unethical concept of fall in love with a married man. It is indeed a grave practice of inculcating bad thoughts into the minds of innocent rural wo men which ultimately destroys the family relations and societal conditions.

\subsection{Anti-social behavior in women}

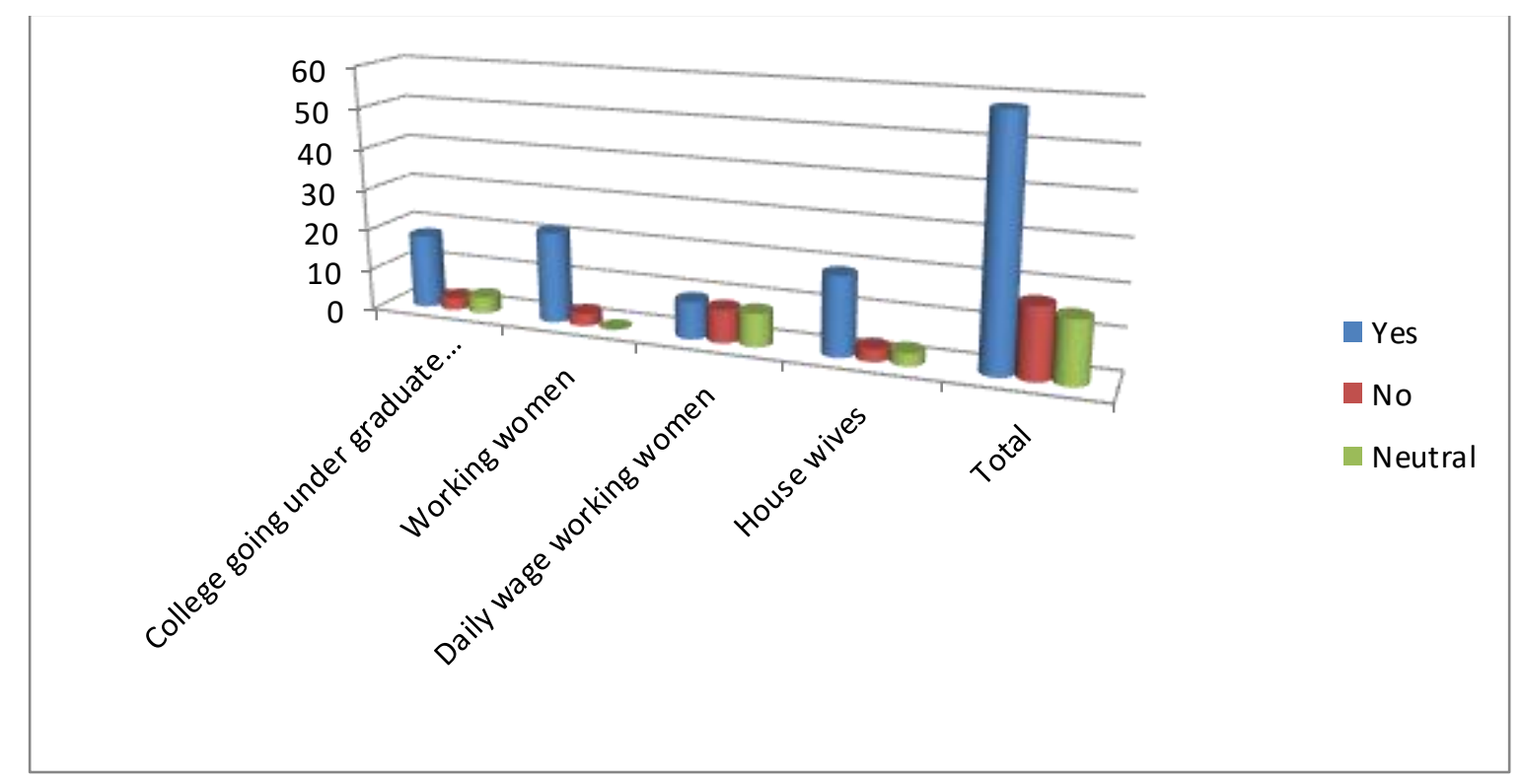

Around $58 \%$ of the women are agreed that it was shown clearly in the serials that women are portrayed in a different way which is not real in our society. Society has a certain expectations on women as they manage everything with patience; they are kind, obedient and loving. More than these qualities women role in a family plays a vital role but the contemporary serials were exaggerating the anti-social elements and making a woman is prime villain to another women.

\subsection{Cruelty of women in serials.}

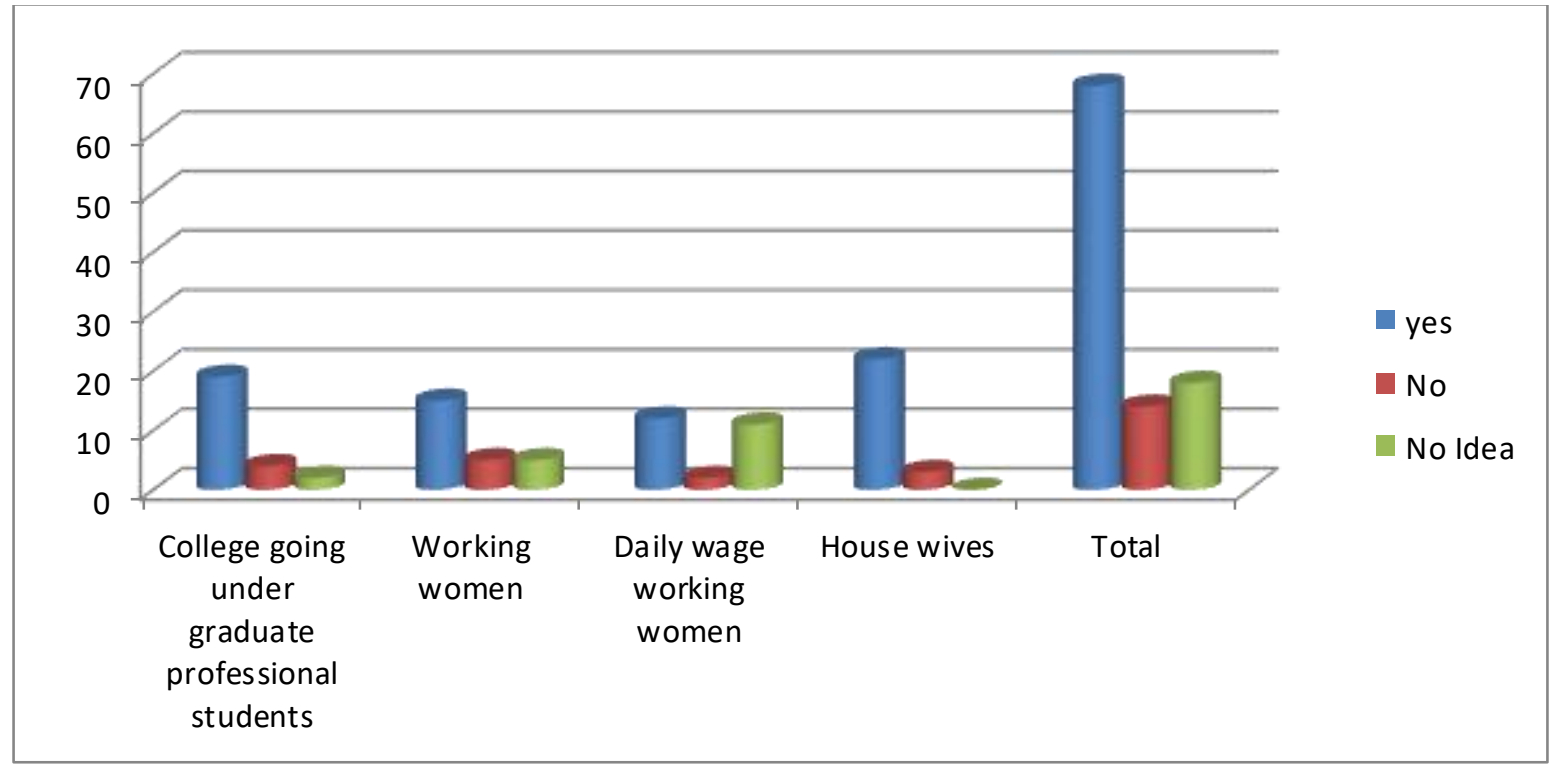


$68 \%$ of the women agreed that women are shown cruel in the daily serials. Most of the wo men replied that a character named Monitha from Karthika Deepam, highest TRP rated serial in MAA TV is the example for this. Deepa, dark skinned lady is the main character of the serial karthika deepam wedded to Karthik whom was deeply loved by Monitha. Monitha get the couple separated with her evil plans to marry him again. Director used soliloquies to depict the cruelty of Monitha and her plans to the audience. Monitha is the main villain of the plot though we have many male characters which shows that a woman is portrayed in a way that women cant even trust another women.

\subsection{The cause for excessive romance in English}

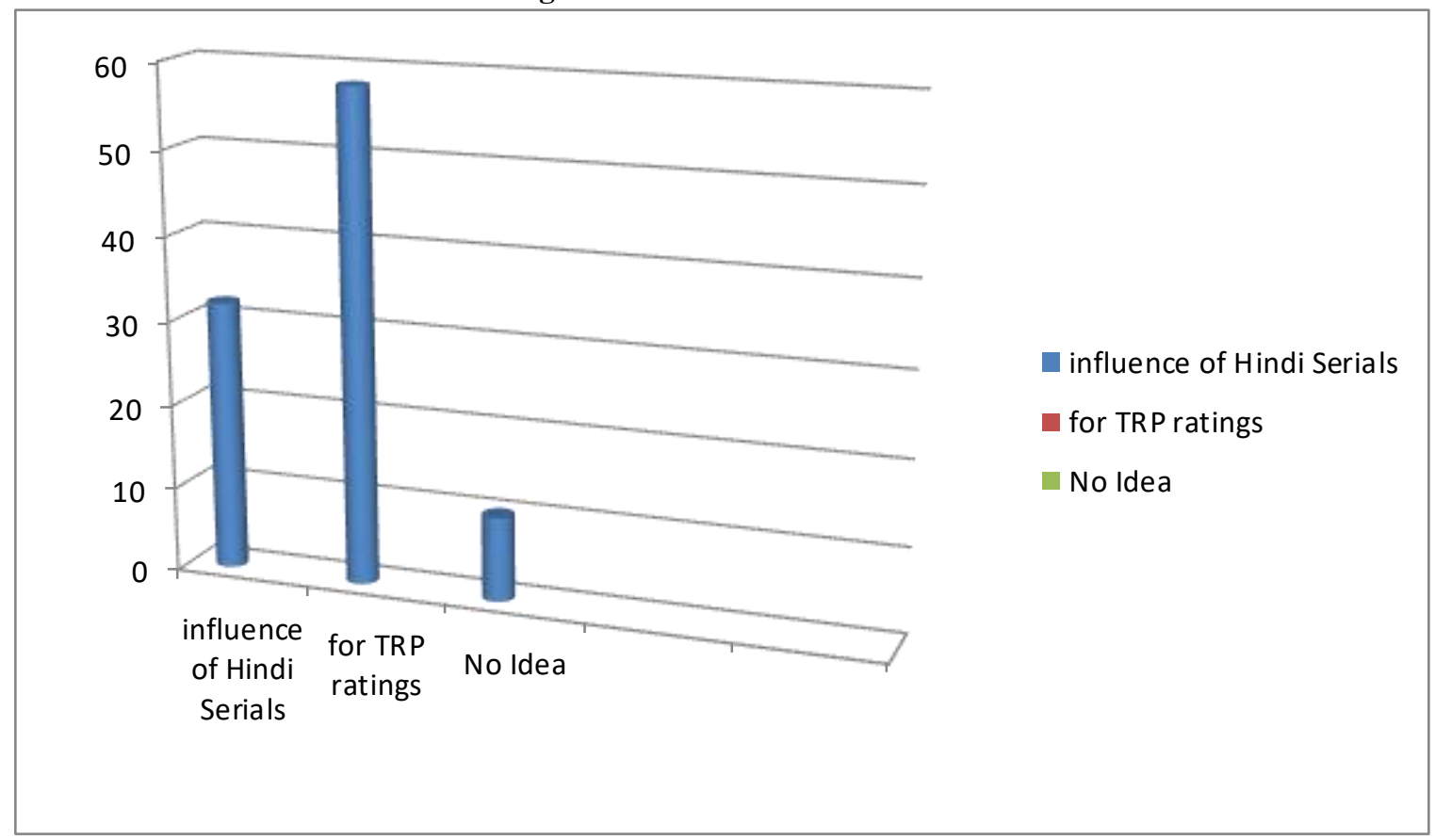

Around $58 \%$ of the women said that it is because of the Hindi Serials they are showing excessive romance in Telugu Serials. They even told most of the serials are copyrighted from Hindi serials automatically they are imitating the same which was shown in the Hindi serials. But they are objecting this kind of move in daily serials as these kind of scenes influence the youngsters and even children. Most of the women said AGNI SAKSHI is the example for excessive romance.

$30 \%$ of the replies elucidated that Television channels are mostly concentrating on the TRPs rather than the influence of those on our society. They are concentrating on the content which can make the serial lengthy by adding negative shades to women.

\section{CONCLUSION}

Based on my understanding from the in depth interview techniques on 100 Godavari Districts women, I find out that serials became a favorite pass time for many of the women and they opt HOTSTAR to continue watching if they miss the episode. This shows the influence of daily serials in the life of every wo man. $68 \%$ out of all the women who watch serials regularly agreed that serials have all the elements which I have stated in my objective like cruelty, excessive romance, extramarital affairs, anti-social elements. My study revealed that these serials and the above said elements influence our families in a very bad way as Aristotle said "what we do regularly is what our personality is" this quotes says a lot even in this $21^{\text {st }}$ century. Our mind is an empty vessel what we pour in that will reflect as our behavior and personality. These serials are imposing all unrealistic elements in the innocent minds of these Godavari district women. 


\section{RECOMMENDATIONS}

The study needs extensive research on large no of people to recommend. My finding through this study would be used as a reference to study further in the same field.

\section{REFERENCES}

[1] Welcome to East Godavari District Web Portal | District East Godavari, Government of Andhra Pradesh. (2019). Retrieved from https://eastgodavari.nic.in

[2] West Godavari District, Government of Andhra Pradesh | A Rice Bowl of Andhra Pradesh. (2019). Retrieved from https://westgodavari.nic.in

[3] Arti Bhatt, Dept of Jounalis $m$ and media studies, A Study of viewing habits among Rural Women of Tehri Garhwal District. IOSR Journalof Humanities and Social sciences.Pg: 44-56

[4] Vijay Lakshmi.P, Foreign Television and Indian Youth changing minds, New Delhi

[5] Raghavan and Priya: family, politics and popular television:an ethnographic study of viewing on Indian serial melodrama, Victoria University.

[6] K. Anitha, who owns Media content, Owners or Viewers? A Study on Telugu Soap Operas, International Journal of Communication and Social Research, Vol 3 July- Dec 2015 